\title{
OnabotulinumtoxinA injections for atypical odontalgia: an open-label study on nine patients
}

This article was published in the following Dove Press journal: Journal of Pain Research

\author{
Rafael García-Sáez' \\ Álvaro Gutiérrez-Viedma ${ }^{1,2}$ \\ Nuria González-García' \\ Víctor Gómez-Mayordomo' \\ Jesús Porta-Etessam ${ }^{1,2}$ \\ María-Luz Cuadrado',2 \\ 'Headache Unit, Department of \\ Neurology, Instituto de Investigación \\ Sanitaria del Hospital Clínico San \\ Carlos (IdISSC), Madrid, Spain; \\ ${ }^{2}$ Department of Medicine, School of \\ Medicine, Universidad Complutense \\ de Madrid (UCM), Madrid, Spain
}

Correspondence: María-Luz Cuadrado Department of Neurology, Hospital Clínico San Carlos, Calle Prof. Martín Lagos, S/N, 28040 Madrid, Spain

Tel +34 9l 33035 II

Fax +34913303512

Email mlcuadrado@med.ucm.es
Background: Atypical odontalgia (AO) manifests as continuous pain in the region of one or several teeth, in the absence of signs of dental pathology. Currently, there is insufficient evidence to establish treatment guidelines for AO. The aim of this study was to describe the effectiveness and safety of treatment with OnabotulinumtoxinA (OnabotA) on a series of patients with AO. Methods: Nine patients with AO (four males and five females, aged between 31 and 77 years) received injections of OnabotA in the region of pain. The dosage used in each procedure ranged between 10 and $30 \mathrm{U}$, spread between 4 and 12 injection sites along the gums $(n=9)$, the lips $(n=3)$, and the hard palate $(n=1)$. The median follow-up time was 27 months (interquartile range, IQR 20-40) and the median number of injection sessions per patient was seven (IQR 4.5-9). The assessment variables included the change in the maximal intensity of pain on a $0-10$ numerical rating scale (NRS), the response latency, and the duration of the effect.

Results: All patients experienced a significant improvement, with $\geq 50 \%$ of reduction in the intensity of the maximal pain. The median of reduction of maximal pain after treatment was six points on the NRS (IQR 5-8.5). The response latency was 2-15 days and the duration of the effect was 2-6 months. No significant adverse reactions were registered.

Conclusion: OnabotA may be a safe and effective option for the treatment of AO.

Keywords: neuropathic pain, orofacial pain, painful trigeminal neuropathy, persistent dentoalveolar pain, persistent idiopathic facial pain, phantom tooth pain

\section{Introduction}

Atypical odontalgia (AO) constitutes one of the multiple causes of orofacial pain, affecting up to $6 \%$ in patients following endodontic procedures. ${ }^{1,2}$ According to the literature, this condition is known under several names, such as persistent dentoalveolar pain ${ }^{3}$ or phantom tooth pain. ${ }^{4}$ According to the third edition of the International Classification of Headache Disorders (ICHD-3), currently this condition is considered to be a subtype of persistent idiopathic facial pain. However, seeing as on occasions there is a traumatic trigger, according to the ICHD-3, this condition may also be considered to be a subform of post-traumatic painful trigeminal neuropathy. ${ }^{5}$ Despite the heterogeneity in the classification and the diagnostic criteria proposed in the literature, the clinical characteristics are well defined. AO leads to a situation of continuous pain, located on one or several teeth or in the alveolus after a tooth extraction, in the absence of signs of dental illness upon examination or in the imaging tests. Within the temporal pattern of chronic pain, some patients experience acute worsening. The quality of pain is variable, and it can irradiate to the maxillary and jaw region and/or other orofacial regions. 
On occasions, hypo- or hyperesthesia and/or allodynia may exist in the symptomatic area. ${ }^{1}$

The pathophysiology of AO is not fully known, and several hypotheses have been proposed. The most supported hypothesis suggests a neuropathic origin, considering that trauma to teeth and/or periodontal structures may alter the tissue continuity and, therefore, generate changes in the periodontal nerve plexus leading to the appearance of peripheral sensitization. ${ }^{6}$ This hypothesis is based on some studies of animal models of dental extraction that demonstrate that the loss of dental pulp in an inflammatory environment induces pathological changes in the periodontal plexus. ${ }^{7}$ Furthermore, the abnormalities found during neurophysiological tests, for example, a decreased response of the blink reflex, ${ }^{8}$ and in quantitative sensory testing ${ }^{9}$ in patients with $\mathrm{AO}$ suggest the existence of abnormalities in the processing of trigeminal nociceptive information.

The treatment of this condition is based on the results of case series and recommendations by experts, most of which recommend the use of tricyclic antidepressants and antiepileptics. ${ }^{1,6,10}$ Nonetheless, their effect is usually insufficient and often there are tolerance problems that limit their use. Other therapeutic modalities, such as the local injection of anesthetics, ${ }^{11}$ have also demonstrated inconsistent results. A therapeutic alternative could be the local injection of botulinum toxin, considering this was found to be effective in a case series of four patients published in 2016 by our own research group, ${ }^{12}$ as well as one case report. ${ }^{13}$

Onabotulinumtoxin A (OnabotA) is a polypeptide that has an analgesic effect, on the peripheral level, as well as centrally. ${ }^{14}$ Although its mechanism of action is not completely known, it has demonstrated to be effective in the treatment of many types of neuropathic pain, such as trigeminal neuralgia (TN), ${ }^{15-18}$ post-herpetic neuralgia, ${ }^{19}$ and painful diabetic neuropathy. ${ }^{20}$ The aim of this study was to describe our experience with the local injection of OnabotA on a series of nine patients, extending the follow-up of the previously reported four patients with the addition of five new patients.

\section{Methods}

From January 2014 to April 2018, we performed a quasiexperimental, prospective, open-label, non-controlled study on a consecutive cohort of patients with a diagnosis of $\mathrm{AO}$ treated via local injection of OnabotA at the Headache Unit of the Hospital Clínico San Carlos (HCSC). Inclusion criteria were 1 ) age over $18 ; 2$ ) AO according to the criteria of the ICHD-3; and 3) stable pharmacological treatment over the previous three months with a partial or null effect. Exclusion criteria were 1) pregnancy or nursing; 2) history of drug or alcohol abuse; 3) history of a major psychiatric disorder; 4) history of an unstable medical condition (eg, neoplastic); 5) history of other chronic pain syndromes; 6) any dental or orthodontic procedures within the past three months; 7) known hypersensitivity to botulinum toxin; and 8) inability to understand and complete an informed consent or to conduct a proper record of the pain. The study received approval from the Clinical Research Ethics Committee of the HCSC, and all the patients signed the informed consent.

In this series, four patients were included from a prior study performed by our group (case no. 1-4), ${ }^{12}$ extending their follow-up time. OnabotA was distributed upon several sites of the gingival mucosa in the symptomatic area, adding additional injection sites in other symptomatic regions of the oral cavity and/or adjacent facial regions (Figure 1), up to a maximum of 12 sites and a maximal dosage of $30 \mathrm{U}$. The total dose of OnabotA and the number of injection points were adapted to the extent of the painful area and to the needs of each patient. A dilution of $5 \mathrm{U}$ per $0.1 \mathrm{~mL}$ of physiological saline solution $0.9 \%$ was performed, injecting $2.5 \mathrm{U}$ per site using a sterile 30 -gauge needle. Repeated procedures were performed when requested by the patients after at least 3 months.
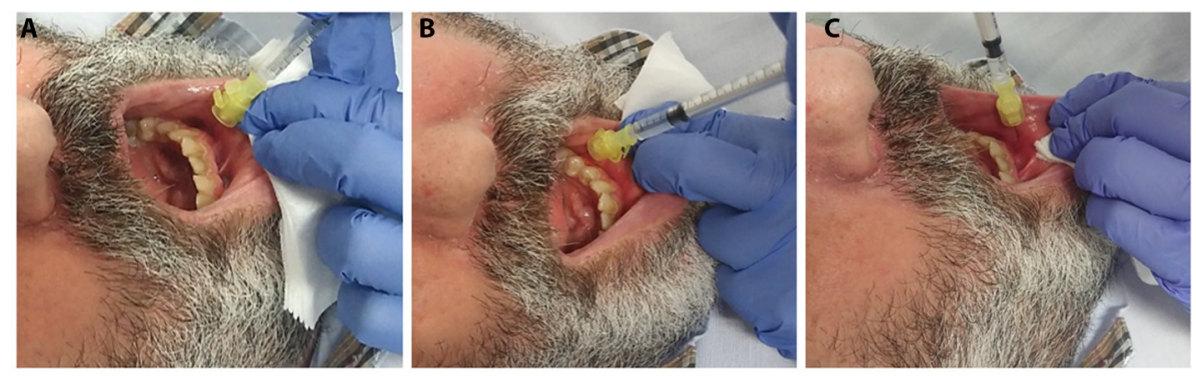

Figure I (A and B) Injection of OnabotulinumtoxinA (OnabotA) into the facial papillae of the interdental gingiva. (C) Injection of OnabotA into the labial mucosa (patient 5). 
The assessment variables were the following: the minimum and maximum values of pain intensity both at baseline and after treatment (measured with the $0-10$ numeric rating scale of pain, NRS), the change in the maximal intensity of pain on the NRS, the time between treatment and the beginning of the analgesic effect, and the duration of this effect from the time of the intervention. The response rate was defined as the proportion of patients showing a reduction of $50 \%$ or greater in the maximal pain. Furthermore, the adverse reactions attributable to either the procedure itself or the drug were also registered.

\section{Results}

Nine patients were included in the study (five females and four males), aged between 31 and 77 years (median age 51 years). The median age at the beginning of the symptoms was 38 years (interquartile range, IQR, 31.5-42.5), with five of the nine patients presenting a dental extraction as a precipitating event. All subjects presented chronic dentoalveolar pain, without data of dental pathology, having being evaluated by at least one dentist, and with normal blood tests (including erythrocyte sedimentation rate and C-reactive protein) and imaging (orthopantomography and computerized tomography of the maxillofacial region). The median of maximal pain was eight points on the NRS (IQR 7.5-10). All patients had received treatment with antidepressants, antiepileptics, nonsteroidal anti-inflammatory drugs, opioids, and/or simple analgesics for over six months, without a satisfactory response. The details regarding the demographic and clinical characteristics of participants are presented in Table 1.

The nine patients received injections in the facial papillae of the interdental gingiva on the painful region. All patients with a history of dental extraction presented phantom pain in the dental alveoli of the extracted teeth; in these cases, injection sites were added in these alveoli. Furthermore, three patients received OnabotA infiltration in the subcutaneous tissue of the hemi-lip on the symptomatic side and one patient on the hard palate, as these patients presented irradiated pain to these areas. The total dosage of OnabotA per cycle varied from 10 to $30 \mathrm{U}$ (median $20 \mathrm{U}$ ), spread out between 4 and 12 injection sites (median eight sites). The median follow-up time was 27 months (IQR 20-40) and the median number of injection sessions per patient was seven (IQR 4.5-9).

After treatment with OnabotA, all patients experienced $\geq 50 \%$ reduction in the intensity of their maximal pain so that the pain was rated between 0 and 3 on the NRS. One patient obtained a complete remission (patient no. 3) and four patients were left with intermittent mild pain (patients no. 2, 4, 6, and 8), whereas the remainder reported mild continuous pain. The median of reduction of maximal pain after treatment was six points on the NRS (IQR 5-8.5). Furthermore, all patients experienced a reduction of the painful area and the use of drugs, to the extent that patients $1,3,6$, and 9 were able to interrupt the use of oral medication. The response latency was $2-15$ days (median, 7 days; IQR 7-14) and the duration of the effect was 2-6 months. The magnitude of reported effect remained stable, but some patients had longer duration of effect after several treatment sessions (patients 1, 2, 3, 5, and 6). No significant adverse reactions were registered.

\section{Discussion}

$\mathrm{AO}$ is a therapeutic challenge as there is insufficient evidence to establish treatment guidelines or recommendations. . $^{1,2,9,10}$ The different topical and systemic treatments that have been used show heterogeneous and often suboptimal results, as well as adverse effects that limit their use. Seeing as the most accepted pathophysiological hypothesis suggests a neuropathic origin, ${ }^{6}$ it is logical to assess therapeutic alternatives with demonstrated efficiency in cases of neuropathic pain, such as the local injection of OnabotA. In this sense, our research group published a series of four cases of $\mathrm{AO}$ in 2016, which is included in the present series, and in which a complete or almost complete response was obtained with the infiltration of OnabotA. ${ }^{12}$ Herrero-Babiloni et al reported a similar response in another patient in the same year. ${ }^{13}$ In the current series all nine patients experienced significant pain relief, with a latency of 2-15 days and a duration of the effect of 2-6 months. Otherwise, none of our nine patients had significant adverse events while the case described by Herrero-Babiloni only reported mild side effects (dryness in the area of injection and facial asymmetry).

Although the mechanism via which OnabotA exercises an analgesic effect is not completely understood, it is known that the toxin degrades the SNAP-25 protein (synaptosomal-associated protein of $25 \mathrm{kDa}$ ), which is a type of SNARE protein (soluble N-ethylmaleimide sensitive factor attachment protein receptor) necessary for the exocytosis of certain neurotransmitters in the terminal axon. In this manner, the liberation of local nociceptive neuropeptides and neurotransmitters such as calcitonin gene-related peptide, substance $\mathrm{P}$, bradykinin, and glutamate is inhibited, which leads to a reduction of the peripheral pain sensitization. Other complementary mechanisms have also been proposed, such as the decreased translocation of the transient receptor potential vanilloid 
Table I Demographic and clinical features of the patients included in this series

\begin{tabular}{|c|c|c|c|c|}
\hline Patient no. & $\mathbf{I}$ & 2 & 3 & 4 \\
\hline Sex & Male & Female & Male & Female \\
\hline Age, years & 31 & 72 & 53 & 52 \\
\hline Age at onset, years & 24 & 32 & 38 & 44 \\
\hline Previous dental extraction & First left upper molar & No & No & No \\
\hline Previous treatment & $\begin{array}{l}\text { Amitriptyline, CBZ, GBP, } \\
\text { PGB, LCS, VPA, ZNS, } \\
\text { duloxetine }\end{array}$ & Amitriptyline, CBZ & CBZ, DPH & Ibuprofen, tramadol \\
\hline Current treatment & Tramadol & $\begin{array}{l}\text { Venlafaxine, clonazepam, } \\
\text { tramadol }\end{array}$ & $\begin{array}{l}\text { PGB, tramadol, } \\
\text { metamizole }\end{array}$ & Amitriptyline, PGB \\
\hline Location & $\begin{array}{l}\text { Left upper dental arch and } \\
\text { missing molar }\end{array}$ & $\begin{array}{l}\text { Superior and inferior } \\
\text { paramedian dental arches }\end{array}$ & Right upper dental arch & $\begin{array}{l}\text { Left lower dental } \\
\text { arch }\end{array}$ \\
\hline Spread of the pain & $\begin{array}{l}\text { Left lower dental arch } \\
\text { (exacerbations) and hard } \\
\text { palate }\end{array}$ & Upper lip (continuous) & $\begin{array}{l}\text { Ipsilateral pre-auricular } \\
\text { region (exacerbations) }\end{array}$ & $\begin{array}{l}\text { Ipsilateral jaw } \\
\text { (continuous) }\end{array}$ \\
\hline Quality & Dull, throbbing & Burning & Pressing, throbbing & Throbbing \\
\hline Temporal pattern & $\begin{array}{l}\text { Continuous with } \\
\text { exacerbations }\end{array}$ & Continuous & $\begin{array}{l}\text { Continuous with } \\
\text { exacerbations }\end{array}$ & $\begin{array}{l}\text { Continuous with } \\
\text { exacerbations }\end{array}$ \\
\hline Intensity (NRS) & $8-10$ & 7 & $1-10$ & $2-8$ \\
\hline Injection sites ${ }^{\mathrm{a}}$ (no. of injection points) & $\begin{array}{l}\text { Left upper gum (4), left } \\
\text { lower gum (4) and hard } \\
\text { palate ( } 2)\end{array}$ & $\begin{array}{l}\text { Upper gum (4), lower } \\
\text { gum (4) and upper lip (4); } \\
\text { paramedian distribution }\end{array}$ & Right upper gum (6) & Left lower gum (8) \\
\hline Total no. of injection points & 10 & 12 & 6 & 8 \\
\hline Total dosage OnabotA $(U)$ & 25 & 30 & 15 & 20 \\
\hline Latency for analgesic effect (days) & 7 & 10 & 14 & 7 \\
\hline Intensity of pain after injections (NRS) & $\mathrm{I}$ & $0-2$ & 0 & $0-2$ \\
\hline Duration of analgesic effect (months) & $3-5$ & $3-4$ & $2-4$ & 6 \\
\hline Follow-up (months) & 48 & 48 & 32 & 28 \\
\hline No. of injection sessions & 10 & 10 & 8 & 8 \\
\hline Interval between sessions (months) & $3-6$ & $3-7$ & $3-7$ & $3-7$ \\
\hline Adverse effects & No & No & No & No \\
\hline
\end{tabular}

Notes: a Gums were injected at the facial papillae over the symptomatic area, with additional injection points in the dental alveoli in patients with previous dental extraction and pain in the missing tooth/teeth. NRS: 0 , no pain; 10, the worst imaginable pain.

Abbreviations: CBZ, carbamazepine; DPH, phenytoin; ESL, eslicarbazepine; GBP, gabapentin; LCS, lacosamide; NRS, numeric rating scale of pain; OnabotA, OnabotulinumtoxinA; PGB, pregabalin; VPA, valproic; ZNS, zonisamide.

1 (TRPV1). The decrease in the peripheral sensitization leads to a decrease in the central sensitization, with the corresponding reduction in pain. ${ }^{14}$

Our results and those of Herrero-Babiloni et $\mathrm{al}^{13}$ are in consonance with those described in other cases of neuropathic pain treated using OnabotA. In 2016, a meta-analysis was published that included four randomized controlled clinical trials (RCTs), in which a greater effectiveness was reported for the control of pain using OnabotA when compared to the use of a placebo in the treatment of the TN. ${ }^{17}$ The latency of the therapeutic effect was 1-2 weeks, the duration of the effect was less than three months, and no severe adverse effects were registered. The dosage of injected OnabotA varied between 25 and $100 \mathrm{U}$, although one of the RCTs included found that low dosages $(25 \mathrm{U})$ had a similar effect to high dosages $(75 \mathrm{U}) .{ }^{18}$ Furthermore, in an open clinical trial not included in the meta-analysis, a clinical response was observed with even lower dosages of OnabotA. ${ }^{15}$ All these characteristics were similar in our study, as well as in
RCTs of OnabotA in post-herpetic neuralgia ${ }^{19}$ and diabetic neuropathy. ${ }^{20}$

\section{Conclusion}

Our study suggests that local injections of OnabotA may be an effective and safe therapeutic option for the treatment of AO. Nonetheless, further RCTs are needed to corroborate these findings with a greater level of scientific evidence. Moreover, future studies could help to determine the influence of the patients' clinical and demographic characteristics or the presence of pain-related biomarkers on the therapeutic response. Furthermore, it would be interesting to explore the effect of OnabotA in other orofacial pains of the spectrum of persistent idiopathic facial pain.

\section{Acknowledgments}

This study was presented, in part, at the LXIX Annual Meeting of the Spanish Neurological Society (Valencia, Spain, November 21-25, 2017). Dr Álvaro Gutiérrez-Viedma was 


\begin{tabular}{|c|c|c|c|c|}
\hline 5 & 6 & 7 & 8 & 9 \\
\hline Male & Male & Female & Female & Female \\
\hline 51 & 46 & 48 & 42 & 77 \\
\hline 31 & 46 & 33 & 41 & 40 \\
\hline Third left lower molar & No & Left upper molars & Second left lower molar & First left lower molar \\
\hline ESL & Ibuprofen, metamizole & CBZ, ESL & Ibuprofen, metamizole & ESL \\
\hline GBP, fluoxetine & Oxicam, tramadol & Amitriptyline & Ibuprofen, metamizole & GBP \\
\hline $\begin{array}{l}\text { Missing molar and left side of } \\
\text { lower lip }\end{array}$ & Right lower dental arch & $\begin{array}{l}\text { Left upper dental arch and } \\
\text { missing molars }\end{array}$ & Missing molar & Missing molar \\
\hline $\begin{array}{l}\text { Left lower dental arch } \\
\text { (continuous) }\end{array}$ & $\begin{array}{l}\text { Ipsilateral mandibular } \\
\text { angle }\end{array}$ & $\begin{array}{l}\text { Left side of upper lip } \\
\text { (exacerbations) }\end{array}$ & No & Left lower dental arch \\
\hline Pressing & Electric & Pressing & Throbbing & Dull \\
\hline Continuous & $\begin{array}{l}\text { Continuous with } \\
\text { exacerbations }\end{array}$ & Continuous with exacerbations & $\begin{array}{l}\text { Continuous with } \\
\text { exacerbations }\end{array}$ & Continuous \\
\hline $5-8$ & $8-10$ & $2-10$ & $5-8$ & 4 \\
\hline $\begin{array}{l}\text { Left lower gum (6) and left side } \\
\text { of the lower lip (2) }\end{array}$ & Right lower gum (6) & $\begin{array}{l}\text { Left upper gum (6) and left side } \\
\text { of the upper lip ( } 2 \text { ) }\end{array}$ & Left lower gum (4) & Left lower gum (6) \\
\hline 8 & 6 & 8 & 4 & 6 \\
\hline 20 & 15 & 20 & 10 & 15 \\
\hline 14 & 15 & 7 & 2 & 7 \\
\hline $1-3$ & $0-3$ & $1-2$ & $0-3$ & 2 \\
\hline $4-5$ & $3-6$ & 3 & 3 & 3 \\
\hline 27 & 22 & 22 & 18 & 12 \\
\hline 7 & 5 & 5 & 4 & 4 \\
\hline $3-5$ & $3-6$ & $3-9$ & $3-6$ & 3 \\
\hline No & No & No & No & No \\
\hline
\end{tabular}

supported by a grant from the Universidad Complutense de Madrid (UCM, Contrato Fernando de Castro).

\section{Disclosure}

The authors report no conflicts of interest in this work.

\section{References}

1. Melis M, Lobo SL, Ceneviz C, et al. Atypical odontalgia: a review of the literature. Headache. 2003;43(10):1060-1074.

2. Malacarne A, Spierings ELH, Lu C, Maloney GE. Persistent dentoalveolar pain disorder: a comprehensive review. $J$ Endod. 2018;44(2):206-211.

3. Nixdorf DR, Drangsholt MT, Ettlin DA, et al. Classifying orofacial pains: a new proposal of taxonomy based on ontology. J Oral Rehabil. 2012;39(3):161-169.

4. Marbach JJ. Phantom tooth pain. J Endod. 1978;4(12):362-372.

5. Headache Classification Committee of the International Headache Society (IHS). The International Classification of Headache Disorders. 3rd ed. Vol. 38: Cephalalgia; 2018;38(1):1-211.

6. Baad-Hansen L. Atypical odontalgia - pathophysiology and clinical management. J Oral Rehabil. 2008;35(1):1-11.
7. Holland GR. Periapical neural changes after pulpectomy. Oral Surg Oral Med Oral Pathol Oral Radiol Endod. 1995;80(6):726-734.

8. Baad-Hansen L, List T, Kaube H, Jensen TS, Svensson P. Blink reflexes in patients with atypical odontalgia and matched healthy controls. Exp Brain Res. 2006;172(4):498-506.

9. Baad-Hansen L, Pigg M, Ivanovic SE, et al. Intraoral somatosensory abnormalities in patients with atypical odontalgia--a controlled multicenter quantitative sensory testing study. Pain. 2013;154(8): $1287-1294$.

10. Abiko Y, Matsuoka H, Chiba I, Toyofuku A. Current evidence on atypical odontalgia: diagnosis and clinical management. Int $J$ Dent. 2012;2012:518548.

11. List T, Leijon G, Helkimo M, Oster A, Svensson P. Effect of local anesthesia on atypical odontalgia - a randomized controlled trial. Pain. 2006;122(3):306-314.

12. Cuadrado ML, García-Moreno H, Arias JA, Pareja JA. Botulinum neurotoxin type-A for the treatment of atypical odontalgia. Pain Med. 2016;17(9):1717-1721.

13. Herrero Babiloni A, Kapos FP, Nixdorf DR. Intraoral administration of botulinum toxin for trigeminal neuropathic pain. Oral Surg Oral Med Oral Pathol Oral Radiol. 2016;121(6):e148-e153.

14. Guo BL, Zheng CX, Sui BD, Li YQ, Wang YY, Yang YL. A closer look to botulinum neurotoxin type A-induced analgesia. Toxicon. 2013;71:134-139. 
15. Piovesan EJ, Teive HG, Kowacs PA, et al. An open study of botulinum-A toxin treatment of trigeminal neuralgia. Neurology. 2005;65(8):1306-1308.

16. Wu CJ, Lian YJ, Zheng YK, et al. Botulinum toxin type A for the treatment of trigeminal neuralgia: results from a randomized, double-blind, placebo-controlled trial. Cephalalgia. 2012;32(6):443-450.

17. Morra ME, Elgebaly A, Elmaraezy A, et al. Therapeutic efficacy and safety of botulinum toxin A therapy in trigeminal neuralgia: a systematic review and meta-analysis of randomized controlled trials. J Headache Pain. 2016;17(1):63.
18. Zhang H, Lian Y, Ma Y, et al. Two doses of botulinum toxin type A for the treatment of trigeminal neuralgia: observation of therapeutic effect from a randomized, double-blind, placebo-controlled trial. $J$ Headache Pain. 2014;15:65.

19. Apalla Z, Sotiriou E, Lallas A, Lazaridou E, Ioannides D. Botulinum toxin $\mathrm{A}$ in postherpetic neuralgia: a parallel, randomized, double-blind, single-dose, placebo-controlled trial. Clin J Pain. 2013;29(10):857-864.

20. Lakhan SE, Velasco DN, Tepper D. Botulinum toxin-A for painful diabetic neuropathy: a meta-analysis. Pain Med. 2015;16(9): $1773-1780$

\section{Publish your work in this journal}

The Journal of Pain Research is an international, peer reviewed, open access, online journal that welcomes laboratory and clinical findings in the fields of pain research and the prevention and management of pain. Original research, reviews, symposium reports, hypothesis formation and commentaries are all considered for publication.
Dovepress

The manuscript management system is completely online and includes a very quick and fair peer-review system, which is all easy to use. Visit http://www.dovepress.com/testimonials.php to read real quotes from published authors. 